after speaking of milk abscess, its cause and treatment, uses the following language:-

"Panque, impressed with certain theoretical ideas, which it is unnecessary to discuss here, was led to the use of the following liniment:- - extract of belladonna, two scruples; laurel water, two ounces; sulphuric ether, one ounce. This must be well shaken before it is used. It is to be rubbed into the breasts as high as the axillæ, morning and evening, and the breast must be covered with a fine flannel soaked in the liniment. This proceeding must be repeated every day until the swelling disappears, which is usually on the second or third day. The ether has a smell which is very disagreeable to some, but they ought to bear with it, for it adds essentially to the efficacy of the remedy. The subject is of great import. ance, and, at the risk of being tedious, I shall give the whole of what Dr. Schnur says on the following cases:-

E. MI-, a Jewess, short and slender, was married when thirteen years old, to a husband aged fourteen. Immediately after marriage she became subject to hysteria, and the catamenia grew irregular. On the third year after marriage she - became pregnant, and, arriving at her full time, she was delivered of a small but healthy child. She persisted in attempting to nurse her child, althongh her breasts were ill-developed and her general health far too weakly to authorise the attempt. Six hours after its birth the infant was applied to the breast, when she experienced flying stitches passing through them, which soon amounted to positive and conciderable pain. 'The circumference of the mammæ now increased in size, and in twenty-four hours it was found impossible to extract a drop of milk from them, either by rubbing, pressing, or drawing them. The breasts had lost their proper elastic feel, their surface did not yield to the pressure of the finger, neither was it hot and red like the rest of the skin, but it was white and blanched. Her feet were cold, tongue clean, and the bowels gently opened by a saline aperient. The patient tossed about in her bed, and the pain in her breasts was so excessive as to cause her to rave and faint. Her pulse was small, feeble, and contracted, and she was afflicted with constriction of the chest and spasms of the muscles of the neck. Before my arrival the attendants had tried inunction with almond oil, the application of bags containing dried herbs warmed, fomentations of camomile, \&c., and were just going to apply a poultice of linseed meal. Under these circumstances there appeared to be an urgent necessity for calming the general nervous irritability, and diminishing the pain feit in the breasts. To effect this purpose, nothing seemed better calculated than Ranque's liniment, and I therefore caused it to be applied in my presence. After the flannel had been on one hour the skin of the breasts became slightly red, and the patient expressed considerable relief. The tendency to fainting now vanished, and the pulse lost its irritable contracted stroke; nevertheless, she complained of the smell of the ether, which, she said, gave her the headache, and I subsequently substituted alcohol in its place. With the dimiantion of pain, the hardness of the breasts likewise subsided, and in forty-eight hours all traces of the local affection vanished. (Might not the remarkable relief from pain be attributed in part to the anæsthetic effect of the ether? How closely Dr. Schnur passed by the discovery!)

In two somewhat similar cases, says Dr. Schnur, Ranque's liniment produced the most beneficial effects, although not so rapidly as in that just related. In both the smell of the ether was complained of, but I persevered in its use, being convinced that it contributes much to the efficacy of the remedy in causing that redness of the skin which seems essential to its action. (Was not the belladonna more rapidly absorbed from an almost blistered surface?) Although these cases prove that this remedy possesses considerable power, (mark the modesty of Dr. Schnur,) I by no means wish to assert that it is applicable to all cases, or that its success is invariable. On the contrary, I am sure that the kind of cases to which it is applicable are not very numerous, for it must be recollected that in plethoric, robust women, who have enjoyed a good state of health previous to delivery, antiphlogistic and derivative remedies, such as purgatives, are indispensably necessary, and when administered in proper time, have the best effect, often, although not invariably, enabling us to prevent the formation of abscess or induration of the mammæ. It is in delicate women, of a lean habit and slender form, subject to hysteria or fainting, persons whose constitutions have been impaired by previous illness, hæmorrhage after delivery, or by too frequent child-bearing; it is in such persons that Ranque's liniment will be found useful. Its composition, indeed, consisting of narcotics combined with stimulants, seems to point out the cases in which it may prove serviceable."
Neither Dr. Goolden nor Mr. Berry tell us the temperament f their patients, whether robust or not.

In conclusion, I would ask Dr. Goolden if the use of bella donna has any effect on lactation in subsequent child-bearing? I am, Sir, yours truly,

Weymouth, Mass., U.S.A., June, 1853. W. C. B. FIFIELD, M.R.C.S.L.

\section{DETERMINATION OF SULPHUR, AND THE SOLUBILITY IN NITRIC ACID OF SULPHATE OF BARYTA.}

\author{
To the Editor of THE LANCET.
}

Str, - " "There are few substances, " remarks Professor Calvert, in an able paper recently read before the Manchester Philosophical Society, " more frequently met with, and which require, in spite of what some chemists assert, to be determined with greater precaution, than sulphur and its compounds, and it is therefore of the utmost importance to possess exact means of knowing their proportions. If one looks over all the best analytical works of the day, they all assert 'that sulphate of baryta was so insoluble that it was sufficient to add chloride of barium or nitrate of baryta to a solution containing a sulphate, with an excess of acid, in order that the sulphuric acid existing in a menstruum should be exactly determined." "In the paper above alluded to, Professor Calvert states that he is convinced that sulphate of baryta is soluble in acid and water, 1000 grains of nitric acid (sp. gr. 1·167) dissolving two grains (l) of sulphate of baryta, and one grain being taken up by 140,000 grains of water.

Now, as regards the solubility in nitric acid, it is most essential for all analytical chemists to be aware of this, and in future to avoid determining sulphur by oxidation with nitric acid, for, even in the hands of the most expert chemists, the truth will not be arrived at, as evidenced by the following determinations:-A sulphur compound, oxidized by nitric acid with the greatest care, yielded $47 \cdot 47$ per cent. of sulphur, whereas the same, after fusion with nitrate of potassa, and precipitation with nitrate of baryta, \&c., gave $48^{\circ} 09$ per cent. of sulphur. Again, a pure bisulphide, which was known theoretically to contain 53.33 per cent. of sulphur, gave by the nitric acid process $52 \cdot 94$, and by the salpetre fusion $53 \cdot 31$.

Knowing that these facts will prove valuable if given in your extensively-known journal, $I$ beg you to insert them, and remain, Sir,

College of Chemistry, Liverpool, July, 1858.

$$
\text { Yours most respectfully, }
$$$$
\text { Sheridoan Muspratt, M.D., \&c., }
$$

\section{THE NEW REGULATIONS OF THE COLLEGE.}

\section{To the Editor of THE LANCET.}

SIR, - In your leading article of last week you eulogise the new regulations of the College of Surgeons. $I_{x}$ think it will appear to everyone that the examination is inconsistent with the curriculum they prescribe; and that the curriculum itself is deficient in Practical Anatomy everyone knows and must admit. But the College has overlooked the importance of dissections, not only to pass an examination, but for future practice, whether it be medical or surgical. "The examination in anatomy is to be practical upon recently-dissected and prepared parts." This is very good ; but what do they prescribe to meet this? Only two winters' dissections. Now I ask any considerate teacher or diligent student to contrast the old system of three winters' dissections to meet a not very practical examination, with the new system of only two winters' dissections to meet a very practical examination;- - to contrast two courses of physiology, which is a theoretical subject that may be learned by reading, with two courses of practical anatomy, a subject that can only be acquired by considerable dissection. If we get sufficient dissection and hospital practice, with the same able teachers attached to them as we have at present, and a little chemistry, we shall be as able and as competent surgeons and physicians as any of those who have gone before us; for we are not deficient in books on any subject, neither has the rising generation less taste for learning than the past: therefore, the whole of the other classes might be expunged altogether with advantage (it is, in fact, waste of time to attend them), and the time be profitably spent in attending to practical and microscopical anatomy during the first two winters and summers at least.

I am, Sir, your obedient servant,

Edinburgh, July 19th, 1858. 